\title{
Article \\ Effective Photocatalytic Hydrogen Evolution Using Covalent Triazine Framework-Derived Carbon Nitride Nanofiber Containing Carbon Vacancies for Visible-Light-Driven
}

\author{
Liangjing Zhang ${ }^{1,+}$, Aiwu Wang ${ }^{1,+}$, Mei Zhang ${ }^{2}$, Zhengyuan Jin ${ }^{1, *}$, Huan Yi ${ }^{3, *}$ and Meng Wang ${ }^{1,4, *}$ \\ 1 Shenzhen Key Laboratory of Ultraintense Laser and Advanced Material Technology, Center for Advanced \\ Material Diagnostic Technology, Shenzhen Technology University, Shenzhen 518118, China; \\ zhangliangjing@sztu.edu.cn (L.Z.); wangaiwu@sztu.edu.cn (A.W.) \\ 2 School of Materials Science and Engineering, Beijing Institute of Fashion Technology, Beijing 100029, China; \\ 20140027@bift.edu.cn \\ 3 College of Science, Civil Aviation University of China, Tianjin 300300, China \\ 4 Sino-German College of Intelligent Manufacturing, Shenzhen Technology University, Shenzhen 518118, China \\ * Correspondence: jinzhengyuan@sztu.edu.cn (Z.J.); hyi@cauc.edu.cn (H.Y.); wangmeng@sztu.edu.cn (M.W.); \\ Tel.: +86-0755-26532350 (Z.J.) \\ + These authors contributed equally to this work.
}

check for

updates

Citation: Zhang, L.; Wang, A.; Zhang, M.; Jin, Z.; Yi, H.; Wang, M. Effective Photocatalytic Hydrogen Evolution Using Covalent Triazine Framework-Derived Carbon Nitride Nanofiber Containing Carbon Vacancies for Visible-Light-Driven. Appl. Sci. 2021, 11, 7222. https:// doi.org/10.3390/app11167222

Academic Editor: Guixia Zhao

Received: 12 July 2021

Accepted: 1 August 2021

Published: 5 August 2021

Publisher's Note: MDPI stays neutral with regard to jurisdictional claims in published maps and institutional affiliations.

Copyright: (c) 2021 by the authors. Licensee MDPI, Basel, Switzerland. This article is an open access article distributed under the terms and conditions of the Creative Commons Attribution (CC BY) license (https:// creativecommons.org/licenses/by/ $4.0 /)$.

\begin{abstract}
In this study, a novel fibrous carbon nitride (FCN) was prepared from laminated covalent triazine framework (CTF) via pyrolysis, using functionalized 2,5-thiophenedicarboxylic acid and melamine as the precursors. A carbon vacancy was produced by two-step calcination in argon and air atmospheres. These carbon vacancies further exposed the edges and diffusion channels of the FCN nanofibers, which accelerated photogenerated charge transfer and provided more active sites. The FCN was characterized using various techniques and used for $\mathrm{H}_{2}$ evolution under visible-light irradiation. The as-synthesized FCN exhibited excellent stability, and its photocatalytic activity for $\mathrm{H}_{2}$ evolution under visible-light irradiation was 66 times higher than that of bare $\mathrm{C}_{3} \mathrm{~N}_{4}(\mathrm{BCN})$, attaining a maximum $\mathrm{H}_{2}$ evolution rate of $102.63 \mu \mathrm{mol}$ in $6 \mathrm{~h}$. The FCN remained stable following visible-light irradiation at the end of 10 cycles. The FCN benefited from the absorption of solar energy and a large number of active sites. These advantages facilitated the efficient separation of photoexcited electron-hole pairs to hinder charge recombination. This work generates new insights into the preparation of highly effective FCN photocatalysts that may be put to various applications, especially in the fields of energy and environment.
\end{abstract}

Keywords: covalent triazine framework; fibrous carbon nitride; $\mathrm{H}_{2}$ evolution; nanofiber

\section{Introduction}

Hydrogen is regarded as one of the promising alternatives to fossil fuels that may help satisfy the environmental and social requirements for clean and efficient energy. Photocatalytic water splitting under visible-light irradiation is a promising method of producing clean fuel because it generates hydrogen using sunlight [1-3]. Much effort has been directed toward developing highly efficient and stable photocatalysts for water splitting using building blocks and synthesis methods as required.

Carbon nitride $\left(\mathrm{C}_{3} \mathrm{~N}_{4}\right)$, an emerging metal-free visible-light-activated photocatalyst, has been widely studied owing to its excellent optical, thermal, and electrical characteristics and low cost [4-7]. Vacancy defects have been widely used to modify the performance of photocatalytic materials [8]. The fast electron-hole recombination of $\mathrm{C}_{3} \mathrm{~N}_{4}$ greatly limits the improvements of itsphotocatalytic performance [9]. For these reasons, vacancies are generally introduced to promote electron transfer and the band arrangement is modified to inhibit carrier recombination. $\mathrm{C}$ atoms have a larger atomic radius and surface area than $\mathrm{N}$ atoms, can accept more energy, and have a smaller molecular weight, which 
makes it easier to sputter $C$ atoms from the surface. Carbon vacancies can inhibit carrier recombination by capturing photogenerated electrons and holes. Due to the formation of carbon vacancies, $\mathrm{g}-\mathrm{C}_{3} \mathrm{~N}_{4}$ photocatalysts tend to release more photogenerated electrons to narrow the gap [10].

The introduction of porous structures is often accompanied by the formation of vacancies. Liang et al. synthesized porous $\mathrm{g}-\mathrm{C}_{3} \mathrm{~N}_{4}$ nanosheets (HGCNs) with carbon vacancies. In this structure, the holes in the plane produce more active exposed edges and reduce aggregation. Additionally, the carbon vacancies expand the light absorption range to the near-infrared region and reduce the recombination of photogenerated carriers. Consequently, the photocatalytic activity of HGCNs for producing $\mathrm{H}$ is approximately 20 times higher than that of the bulk structure under visible-light irradiation [11]. Li et al. prepared $\mathrm{g}-\mathrm{C}_{3} \mathrm{~N}_{4}$ with carbon vacancy $\left(\mathrm{Cv}-\mathrm{g}-\mathrm{C}_{3} \mathrm{~N}_{4}\right)$ by a simple two-step calcination process. The photocatalytic efficiency of $\mathrm{Cv}-\mathrm{g}-\mathrm{C}_{3} \mathrm{~N}_{4}$ is $12.3 \%$ higher than that of pristine g- $\mathrm{C}_{3} \mathrm{~N}_{4}$. When the amino and carbon vacancies generated by charge compensation appear simultaneously, the carbon vacancy enables $\mathrm{Cv}-\mathrm{g}-\mathrm{C}_{3} \mathrm{~N}_{4}$ to adsorb $\mathrm{O}_{2}$ more strongly via Lewis acid-base interactions between the $\mathrm{N}$ atom of the amino group and $\mathrm{O}_{2}$, and it is easier for $\mathrm{Cv}-\mathrm{g}-\mathrm{C}_{3} \mathrm{~N}_{4}$ to transfer sufficient photogenerated electrons to $\mathrm{O}_{2}$ to produce $\mathrm{O}_{2}{ }^{-}$[10].

The existence of carbon vacancies can promote the effective separation of photogenerated electron-hole pairs. Following characterization using experimental methods and DFT calculations, tuning the formation of terminal amine functional groups around the carbon vacancy can generate preferred docking sites for the co-catalyst, enhancing its proximity [12]. Compared with pristine $\mathrm{g}-\mathrm{C}_{3} \mathrm{~N}_{4}$, the distribution of electrons and holes in the carbon-deficient $\mathrm{g}-\mathrm{C}_{3} \mathrm{~N}_{4}$ is clearly separated, with the majority of the carriers being trapped in the triazine ring fragments where the defects are located. Therefore, the charge transfer between the fragments is centered on the carbon-deficient triazine ring, and it is no longer limited to intra-fragment charge transfer and multi-center charge transfer between fragments [13].

$\mathrm{C}_{3} \mathrm{~N}_{4}$ can be obtained by calcination of melamine or urea as the precursor. In order to further improve the performance of $\mathrm{C}_{3} \mathrm{~N}_{4}$, some researchers use molten salt method and double calcination to obtain $\mathrm{C}_{3} \mathrm{~N}_{4}$ with high activity [14,15]. However, there have been relatively few contemporary studies on pure $\mathrm{C}_{3} \mathrm{~N}_{4}$, and breakthroughs in the photocatalytic performance of such materials mainly rely on the heterogeneous junction with other substances to achieve high catalytic activity. Using metal organic frameworks (MOFs) as templates for high-temperature treatment, ordered and highly porous carbons can be produced. The layered structure of a two-dimensional covalent triazine framework (CTF) synthesized using triazine rings as building blocks provides periodic $\pi$-stacking arrays that facilitate the transport of charge carriers [16]. There has been some recent success in the synthesis of stable CTFs whose structures resemble those of $\mathrm{C}_{3} \mathrm{~N}_{4}$. It was anticipated that $\mathrm{C}_{3} \mathrm{~N}_{4}$ may be produced using this metal-free synthesis from a structurally similar precursor.

In this study, we present a novel method for synthesis of $\mathrm{C}_{3} \mathrm{~N}_{4}$ from CTF, using a two-step heat-treatment in nitrogen and air atmospheres. Using this method, we effectively fabricated FCN nanofibers with a large number of active sites along a crystalline plane identical to that of CTF. Concurrently, carbon vacancies were generated in the FCN, which greatly accelerated the mass transfer and diffusion of photogenerated carriers. Our CTF is fabricated using melamine as a knot, which increases the $\pi-\pi$ interaction between the layers, and 2,5-thiophenedicarboxylic acid building blocks, which modulate the growth under ambient conditions. Selecting triazine-based melamine can improve the crystallinity of the CTFs and impart sufficient electron-deficiency. Owing to the extended light absorption region, abundant reduction sites, and efficient charge transfer, the FCN delivered 66 times higher photocatalytic performance than the BCN. 


\section{Materials and Methods}

\subsection{Synthesis of Carbon Nitride}

Synthesis of CTF: Melamine was first ground and dispersed in $20 \mathrm{~mL}$ DMF. Then, $30 \mathrm{~mL}$ ethanol and $5 \mathrm{~mL}$ deionized water were added and stirred. Next, 2,5-thiophenedicarboxylic acid was added to the mixture under constant magnetic stirring for $30 \mathrm{~min}$. Then, the asprepared solution was transferred to a Teflon-lined stainless steel autoclave with a $100 \mathrm{~mL}$ capacity and heated in an oven at $120^{\circ} \mathrm{C}$ for $18 \mathrm{~h}$. After cooling to room temperature, the sample was collected and rinsed three times with deionized water, and then three times with ethanol and subsequently dried at $65^{\circ} \mathrm{C}$ overnight to obtain the CTF template.

Preparation of CTF-derived $\mathrm{CN}: \mathrm{C}_{3} \mathrm{~N}_{4}$ was synthesized using CTF as a template. The samples were annealed by heating at the rate of $2{ }^{\circ} \mathrm{C} / \mathrm{h}$ in an Ar atmosphere to $550{ }^{\circ} \mathrm{C}$, and the temperature was maintained for $6 \mathrm{~h}$ to obtain $\mathrm{CN}$. Following cooling to room temperature, the as-prepared $\mathrm{CN}$ was collected and ground into a powder for subsequent use. The $\mathrm{CN}$ sample was further heated by transferring it into lidded crucibles, followed by calcination by heating it to $550{ }^{\circ} \mathrm{C}$ at a rate of $2{ }^{\circ} \mathrm{C} / \mathrm{h}$ in air, and retaining that temperature for $6 \mathrm{~h}$. Following cooling down to room temperature, the sample was labeled as FCN. Bare- $\mathrm{C}_{3} \mathrm{~N}_{4}$ was denoted as $\mathrm{BCN}$.

Samples with different molar ratios of melamine and 2,5-thiophenedicarboxylic acid were obtained and denoted as 1:xCN, $(x=1,2,3,4,5)$. For comparison, samples with different amounts of water at identical reaction conditions were denoted as $\mathrm{yH}_{2} \mathrm{O}-\mathrm{CN}$, $(y=0,10,20,30,40,50)$.

\subsection{Characterization}

The crystal structures of the $\mathrm{CN}$ and FCNwere analyzed by X-ray diffraction (XRD, Philips X'pert Pro). FT-IR spectra were recorded on a Perkin Elmer FT-IR Spectrometer. The Brunauer-Emmett-Teller (BET) surface area was determined using a Quantachrome NOVA 2000e surface area analyzer. The composition of $\mathrm{CN}$ and FCN was analyzed by X-ray photoelectron spectroscopy (XPS). Solid-state ultraviolet-visible (UV-vis) diffuse reflectance spectra (DRS) were measured by the Shimadzu UV-2600UV-vis spectrophotometer. The photoluminescence (PL) spectra were measured by the HORIBA Jobin Yvon LabRAM HR system. Morphology of the FCN surface was observed by field emission scanning electron microscopy (FESEM, Hitachi S-4800) and the chemical composition were recorded by energy dispersive spectroscopy (EDS).Structure of FCN was analyzed by high-resolution TEM (HRTEM). Electron spin resonance (ESR) spectra were acquired by ESR spectrometer (JEOL JES-FA200 ESR spectrometer) at room temperature.

\subsection{Photocatalytic Measurements}

The experiments of photocatalytic $\mathrm{H}_{2}$ production were performed in a $500 \mathrm{~mL}$ Pyrex glass reactor under a Xe lamp (CEAULIGHT, CEL-HXF300). The $10 \mathrm{mg}$ catalysts, $10 \mathrm{~mL}$ Triethanolamine, and $100 \mu \mathrm{L} 3 \mathrm{wt}$. Chloroplatinic acid was diluted with deionized water to a volume of $100 \mathrm{~mL}$. the final volume was $100 \mathrm{~mL}$, and then used as the reaction mixture. The triethanolamine (TEOA) was used as the hole-sacrificing agent to prevent oxygen formation. The solution was irradiated using visible light $(\lambda \geq 420 \mathrm{~nm})$ with the power density of $100 \mathrm{~mW} / \mathrm{cm}^{2}$.The rate of $\mathrm{H}_{2}$ generation during the photocatalytic water splitting reaction was performed inside a CLE-SPH2N Pyrex glass reactor (Aulight Ltd., Beijing, China) and was measured to evaluated the photocatalytic performance.

The apparent quantum yield (AQY) of $\mathrm{H}_{2}$ production was measured through 420 , 450,470 , and $550 \mathrm{~nm}$ band-pass filters. The catalyst solution $(20 \mathrm{mg}$ catalysts with $100 \mathrm{~mL}$ water) was irradiated for $12 \mathrm{~h}$. The average intensity of irradiation was determined to be $10 \mathrm{~mW} / \mathrm{cm}^{2}$ and the irradiation area was $10.17 \mathrm{~cm}^{2}$. The AQY was calculated from the equation:

$$
\eta=\frac{2 n}{N} \times 100 \%
$$

where $n$ and $\mathrm{N}$ are the number of $\mathrm{H}_{2}$ molecules and incident photons, respectively. 


\subsection{Photoelectrochemical Measurement}

The obtained samples were fabricated on FTO substrates by drip coating. The sample combined with a drop of alcohol was dispersed in a $5 \mathrm{~mL}$ centrifuge tube and ultrasonicated for $15 \mathrm{~min}$. The samples were dripped onto FTO substrates of $1.5 \mathrm{~cm} \times 1.5 \mathrm{~cm}$ area and subsequently dried at $65^{\circ} \mathrm{C}$ prior to the photoexcitation experiment.

The photocurrent was measured on a $\mathrm{CHI} 660 \mathrm{E}$ electrochemical workstation using a three-electrode system containing $0.5 \mathrm{M} \mathrm{Na}_{2} \mathrm{SO}_{4}$ as the electrolyte, in which the prepared electrode used as the working electrode, $\mathrm{Pt}$ as the counter electrode and the $\mathrm{Ag} / \mathrm{AgCl}$ electrode as the reference electrode. A Xe lamp with a CEL-AM 1.5 filter (CEAULIGHT) was used as the light source. The intensity of the light source was set to $50 \mathrm{mWcm}^{-2}$ by adjusting the distance between the light source and the sample.

\section{Results and Discussion}

\subsection{Characterization of Physical and Chemical Properties}

Figure 1 shows the proposed schematic for the synthesis of CTF-derived carbon nitride. CTF is a framework structure formed by organic functional groups connected by a triazine ring. The designed triazine ring is used as the precursor to generate carbon nitride following calcination. In the first step, melamine and 2,5-thiophenedicarboxylic acid are hydrothermally dissolved in the mixed solution. Covalent-organic frameworks (COFs) can be designed using topology diagrams to guide their structure because their skeletons and pores are designable. The combination of $\mathrm{C}_{3}{ }^{-}$symmetric(e.g., Melamine) knots and $\mathrm{C}_{2}$-symmetric(e.g., 2,5-thiophenedicarboxylic acid) linkers $\left(\mathrm{C}_{3}+\mathrm{C}_{2}\right)$ leads to the formation of hexagonal COFs [17]. Calcination in an Ar atmosphere is an effective method for creating carbon vacancies in $C_{3} N_{4}[10,18]$. Argon molecules absorb large amounts of energy at high temperatures, causing some molecules to move irregularly. Argon molecules in irregular motion will impact the surface of $\mathrm{C}_{3} \mathrm{~N}_{4}$ and transfer energy to the surface atoms. When the energy transferred exceeds the binding energy of the target atom, the atom detaches from the surface, leaving a vacancy. Finally, a highly active photocatalyst modified with carbon vacancy was obtained by two-step calcination under an argon and air atmosphere.

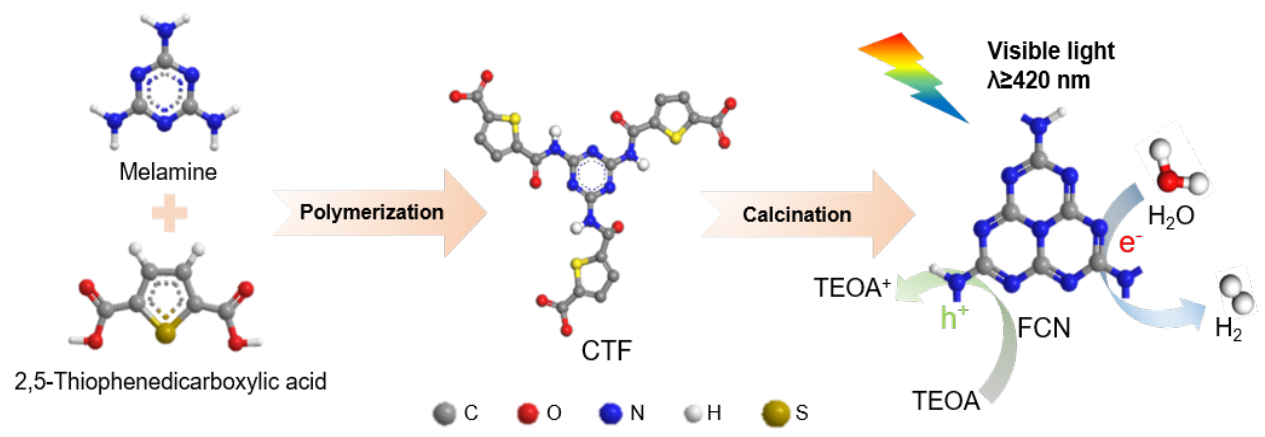

Figure 1. Schematic for the preparation of FCN.

XRD analyses were performed to investigate the phase structure of the samples. The XRD patterns of $\mathrm{CN}$ having different precursor ratios are shown in Figure S1a,b. The diffraction peaks observed at $13.3^{\circ}$ (indexed as (100)) and at $27.2^{\circ}$ (indexed as (002)) of $\mathrm{CN}$ originate from the in-plane structural packing motif (tri-s-triazine structures) and interplane stacking of the aromatic systems of $\mathrm{C}_{3} \mathrm{~N}_{4}$, respectively [19]. As the fraction of water increased, the peaks at $13.0^{\circ}$ remained unchanged, but the peaks at $27.6^{\circ}$ shifted to lower angles, implying that the addition of water to the precursor maintained the inplane structure but increased the interplanar spacing of the crystal. The sharpness of the peak indicates the high crystallinity of the sample that exhibits good photocatalytic performance. This is mainly attributed to the further calcining that can increase the degree of polymerization of $\mathrm{CN}$ and thereby increase its photocatalytic performance. Figure 2a 
shows the two distinct diffraction peaks exhibited by FCN, located at $2 \theta=13.2^{\circ}$ and $27.6^{\circ}$, which indicate that calcination increased the spacing between the in-plane structure and decreased the interplanar spacing of the crystal [4].

FT-IR spectroscopy can identify the functional groups present in the samples (Figures $2 \mathrm{~b}$ and $\mathrm{S} 1 \mathrm{c}-\mathrm{f}$ ). The intense band in the vicinity of $812 \mathrm{~cm}^{-1}$ corresponds to the tri-s-triazine ring mode of CTF [20]. The FCN spectrum contained several peaks between 1215 and $889 \mathrm{~cm}^{-1}$ that were attributed to the stretching vibrations of the $\mathrm{C}-\mathrm{O}-\mathrm{C}$ group [13]. Furthermore, the peaks appearing at 1508 and $1357 \mathrm{~cm}^{-1}$ were assigned to the triazine unit in $\mathrm{CN}$, demonstrating that the chemical framework of $\mathrm{CN}$ was retained following the calcination of CTF. CN presented two peaks in the vicinities of 1637 and $1215 \mathrm{~cm}^{-1}$ that were attributed to $\mathrm{C}-\mathrm{N}$ stretching. The peaks between 3000 and $3400 \mathrm{~cm}^{-1}$ were attributed to the residual $\mathrm{N}-\mathrm{H}$ groups and the $\mathrm{O}-\mathrm{H}$ band. The range is related to the partial hydrogenation of nitrogen on the edges of the layers [21]. Other vibration bands shifted significantly following further heating, indicating that $\mathrm{CN}$ crystallized and functional groups branches were generated [22].

Figure 2c shows the $\mathrm{N}_{2}$ sorption isotherm with an inflection point at low $P / P_{0}$ values and a type IV character typical with $\mathrm{H} 3$ adsorption hysteresis [23]. A narrow distribution of micropores centered at approximately $1 \mathrm{~nm}$ was observed (inset in Figure 2c), which suggests that a large number of micropores exist in these samples. The BET surface area of $\mathrm{CN}$ was $31.3 \mathrm{~m}^{2} \mathrm{~g}^{-1}$ and further heating greatly increased its specific surface area $\left(159 \mathrm{~m}^{2} \mathrm{~g}^{-1}\right)$. The surface area of FCN can be increased 5 times by calcining, and the increased specific surface area can provide a large number of active sites, which improves the catalytic activity (Table 1 ).

Table 1. Specific surface areas and XPS elemental compositions of the samples.

\begin{tabular}{cccccc}
\hline & $\mathbf{S}_{\text {BET }}\left(\mathbf{m}^{2} / \mathbf{g}\right)$ & C(Atomic\%) & N(Atomic\%) & O(Atomic\%) & S(Atomic\%) \\
\hline CTF & 6.0 & 42.5 & 40.0 & 14.1 & 3.4 \\
CN & 31.3 & 44.5 & 52.2 & 3.0 & 0.3 \\
FCN & 159 & 42.6 & 54.7 & 2.4 & 0.2 \\
\hline
\end{tabular}

XPS was performed to further confirm the chemical states and surface elements. The survey XPS spectrum shown in Figure $2 \mathrm{~d}-\mathrm{f}$ verified the presence of $\mathrm{C}, \mathrm{N}$, and $\mathrm{O}$. For the $\mathrm{C}$ 1s core level of $\mathrm{CN}$, two peaks were identified at 284.5 and $288.0 \mathrm{eV}$, corresponding to $s p^{3} \mathrm{C}-\mathrm{C}$ bonds and $\mathrm{C}-\mathrm{N}=\mathrm{C}$ coordination, respectively [24]. While identifying the vacancy of carbon in $\mathrm{C}_{3} \mathrm{~N}_{4}$, the areal ratio between the two $C$ 1s XPS peaks was found to have decreased compared to that for the NC sample due to the reduction of tertiary carbon content. A lower $\mathrm{C} / \mathrm{N}$ ratio compared to the $\mathrm{NC}$ sample could also indicate a higher carbon vacancy. The peak of FCN at $288.0 \mathrm{eV}$ shifted to lower binding energies than in $\mathrm{CN}$, implying that the structure of $\mathrm{C}-\mathrm{N}=\mathrm{C}$ formed from melamine changes during the decomposition of the organic framework and finally forms FCN. Figure 2e presents the N 1s XPS spectra for $\mathrm{CN}$ and FCN. The peak of FCN can be deconvoluted into four peaks at 398.6, 399.8, 401.0, and $404.2 \mathrm{eV}$, corresponding to $\mathrm{C}-\mathrm{N}=\mathrm{C}, \mathrm{N}-(\mathrm{C})_{3}, \mathrm{C}-\mathrm{NH}$, and charge effects on the FCN surface, respectively. The peak of $\mathrm{CN}$ at $398.4 \mathrm{eV}$ was lower than that of $\mathrm{FCN}$, which implies that the process of calcination can affect the $\mathrm{C}-\mathrm{N}=\mathrm{C}$ coordination. In the $\mathrm{O} 1 \mathrm{~s}$ spectra, the samples produced peaks at 531.9 and $531.0 \mathrm{eV}$, respectively, indicating the formation of the $\mathrm{C}-\mathrm{O}, \mathrm{N}-\mathrm{O}$, or $\mathrm{C}-\mathrm{O}-\mathrm{C}$ bonds [25]. The peaks at 531.9 and $533.0 \mathrm{eV}$ shifted to higher binding energies and lower peak areas in $\mathrm{CN}$, which suggests that the bond between carbon and oxygen breaks during the reaction to generate water or gas. 

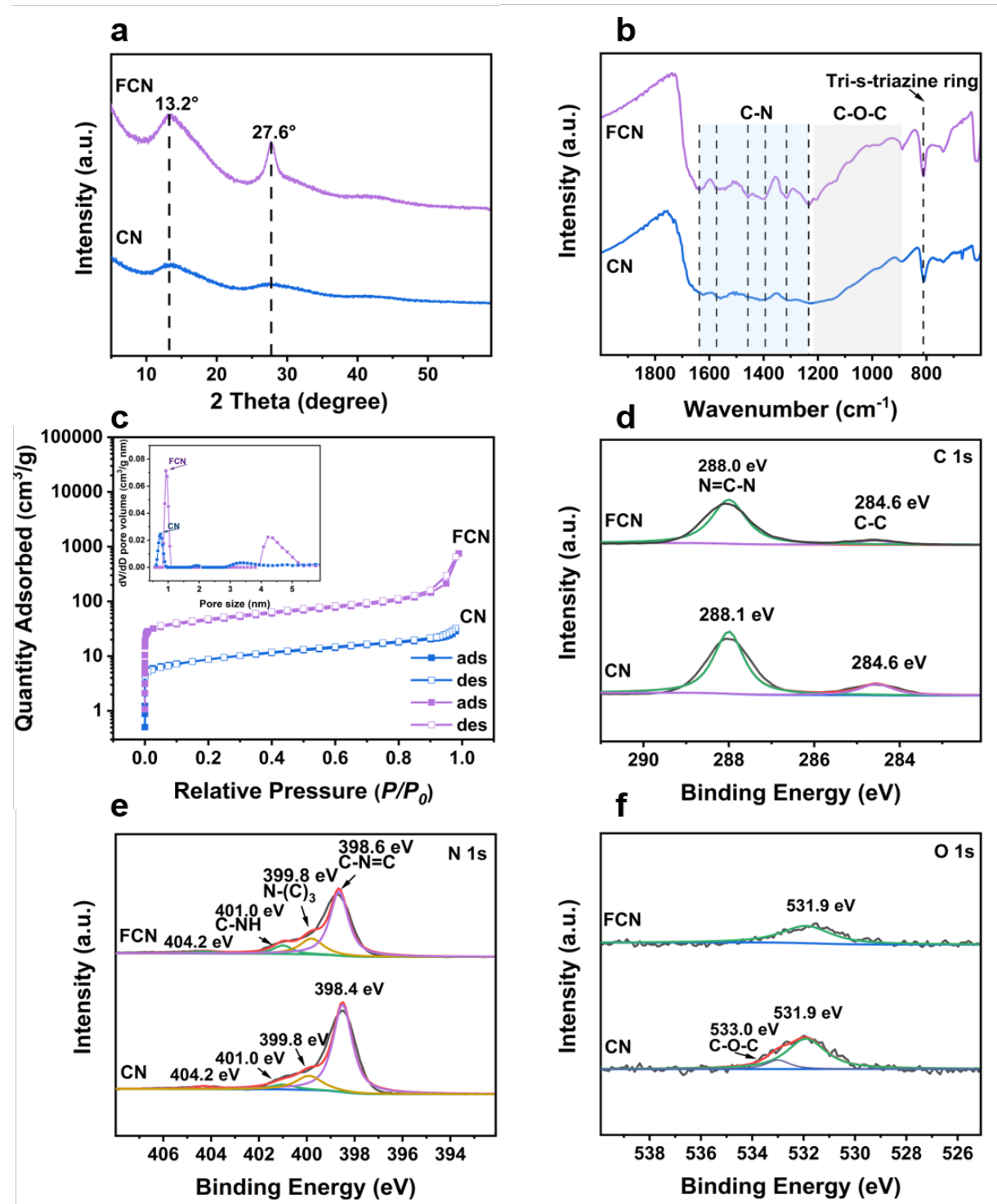

Figure 2. XRD, FT-IR, $N_{2}$ adsorption-desorption isotherms, and XPS characterizations of $\mathrm{CN}$ and FCN. (a) XRD patterns. (b) FT-IR spectra. (c) $N_{2}$ adsorption-desorption isotherms and the corresponding pore-size distribution curves (inset). (d) C 1s XPS spectra, (e) N 1s XPS spectra, and (f) O 1s XPS spectra.

The differences between the morphologies of $\mathrm{CN}$ produced under different conditions were investigated by SEM (Figures 3 and S2). When the water content in the precursor was controlled, $10 \mathrm{H}_{2} \mathrm{O}-\mathrm{CN}$ exhibited the finest fiber morphology. As the water content increased, the fibrous appearance gradually devolved into a blocky structure. When regulating the ratio of the two organic components, the samples exhibited similar fibrous morphologies. Figure S3 shows the SEM images and the corresponding spectra obtained from the energy dispersive X-ray spectroscopy (EDS)of CTF and CN. CTF exhibited a parallelogram-like fibrous structure. EDS element mapping revealed the presence of $C, N$, $\mathrm{O}$, and $\mathrm{S}$ elements. Following calcination, the amount of $\mathrm{S}$ in $\mathrm{CN}$ decreased significantly. This is attributed to the generation of sulfur dioxide when CTF is calcined, which increases the specific surface area of $\mathrm{CN}$ and facilitates the catalytic reaction. Figure $4 \mathrm{a}, \mathrm{b}$ show that the structure of the calcined sample changes from the parallelogram structure of CTF into a fibrous morphology along a certain crystal plane. To further observe the microstructure of the nanofibers, TEM was performed on the FCN sample, and the results are shown in Figure $4 \mathrm{c}, \mathrm{d}$, attesting to the thinness and porosity of each fiber. HRTEM 
images contained clear lattice fringes, and the lattice spacing of $0.28 \mathrm{~nm}$ was assigned to the (002) planes. This interplanar distance was much smaller than that of the common carbon nitride $(0.325 \mathrm{~nm})$ [26].
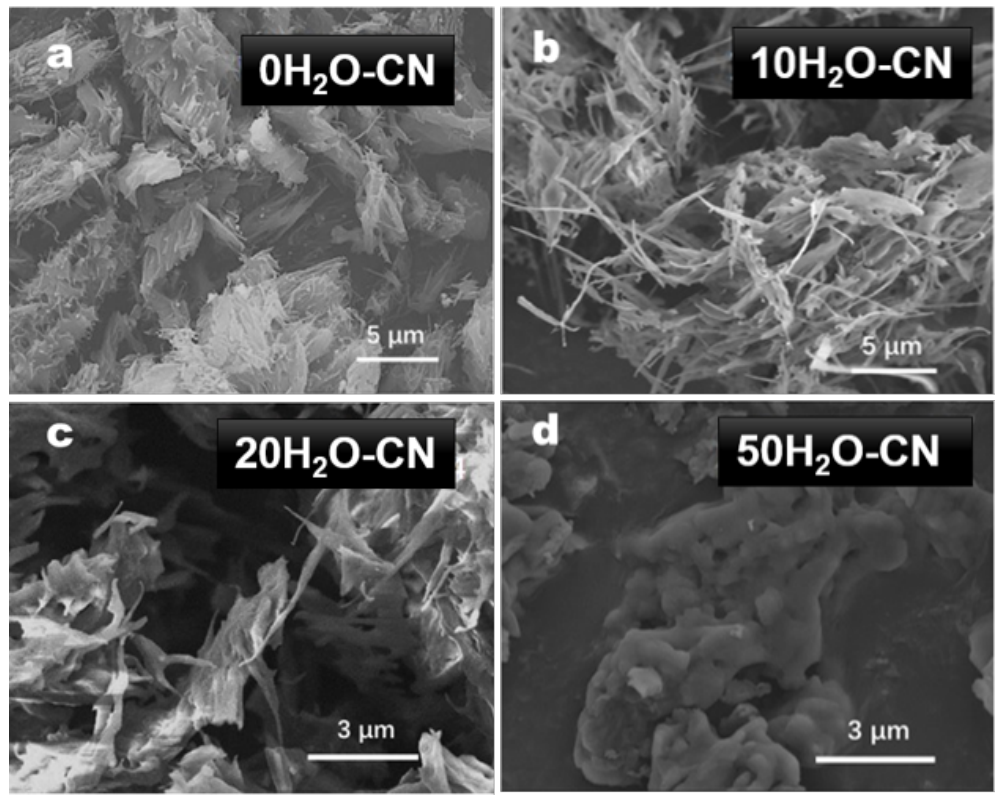

Figure 3. (a-d) SEM images for $\mathrm{xH}_{2} \mathrm{O}-\mathrm{CN}$.
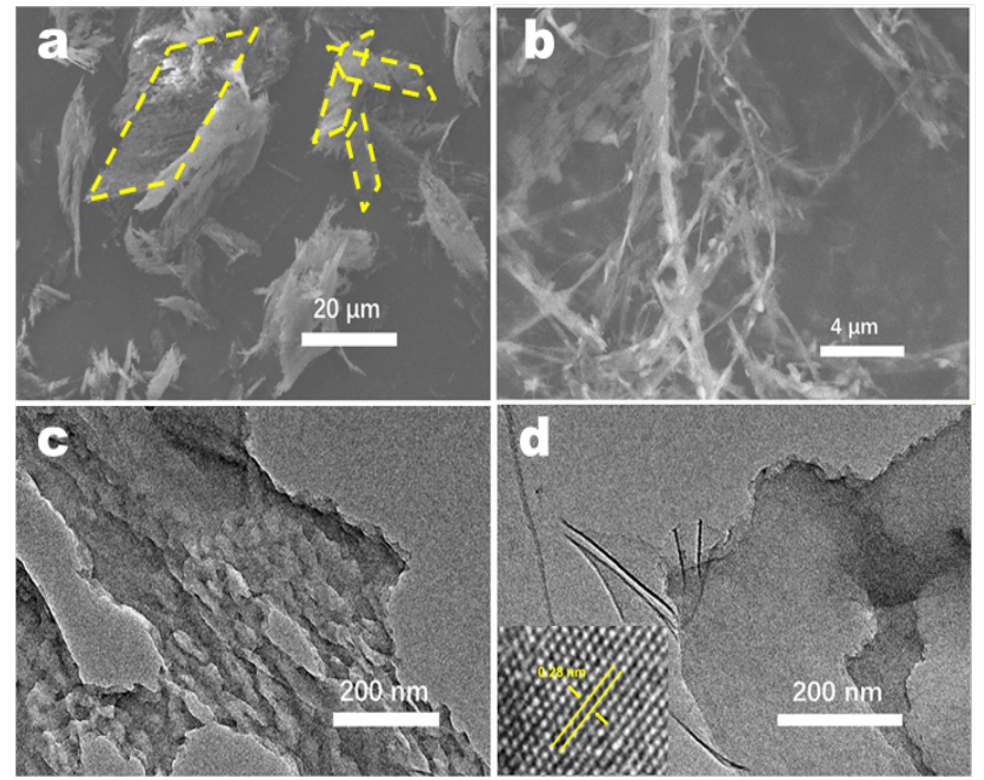

Figure 4. (a,b) SEM images of FCN. (c,d) TEM images of FCN.

\subsection{Characterization of $\mathrm{H}_{2}$ Production from Water Splitting}

The photocatalytic efficiency is measured by the rate of $\mathrm{H}_{2}$ generation from water splitting under visible-light illumination (Figures $5 \mathrm{a}$ and S4a,b). When the water content was controlled, the highest photocatalytic activity was exhibited by $10 \mathrm{H}_{2} \mathrm{O}-\mathrm{CN}$, for which the total $\mathrm{H}_{2}$ production was $7.3 \mu \mathrm{mol}$ following $6 \mathrm{~h}$ of reaction. When the ratio of melamine and 2,5-thiophenedicarboxylic acid was altered, the photocatalytic activity of these five samples varied slightly, which implies that the water content in the precursor is more important. This result is consistent with the XRD analysis. It is evident that $\mathrm{H}_{2}$ generation dramatically increases following further heating to become 14 times higher for FCN than for CN. 
The AQYs of FCN are $2.45 \%, 2.16 \%, 0.95 \%$, and $0.17 \%$ at $420 \mathrm{~nm}, 450 \mathrm{~nm}, 470 \mathrm{~nm}$, and $550 \mathrm{~nm}$, respectively (Figure $5 \mathrm{~b}$ ). The change of the AQY is consistent with the absorption spectrum, indicating that the photoexcitation promotes the $\mathrm{H}_{2}$ formation. It has higher light excitation effect between $420 \mathrm{~nm}$ and $450 \mathrm{~nm}$.

It is evident from Figure $5 c$ that FCN remained stable under visible-light illumination is quite stable following 10 cycles. The yield of $\mathrm{H}_{2}$ steadily increased in the initial three cycles, following which, it oscillated about a mean point. This phenomenon may be due to TEOA being consumed as the reaction proceeds, because excess TEOA molecules participate in the reflection and absorption of incident photons [22]. The effect of excessive TEOA content on $\mathrm{H}_{2}$ production gradually decreases, and the $\mathrm{H}_{2}$ evolution rate is maximized in the third cycle. As the TEOA content continued decreasing till the 10th cycle, the shortage of the sacrificial agent caused partial electron-hole recombination, leading to reduced $\mathrm{H}_{2}$ production. Similarly, we can see from the CN cycle (Figure S5) that the sample showed a small increase in the second cycle, and then the hydrogen production gradually stabilized.

Photoluminescence spectra were used to verify the recombination rate of photoexcited electrons and holes [26,27]. As shown in Figure S4c, the PL spectra of the $\mathrm{OH}_{2} \mathrm{O}-\mathrm{CN}$ and $50 \mathrm{H}_{2} \mathrm{O}-\mathrm{CN}$ exhibited weaker signals, although all the samples exhibited emissions centered approximately at $520 \mathrm{~nm}$. The PL intensity of $10 \mathrm{H}_{2} \mathrm{O}-\mathrm{CN}$ was smaller than $20 \mathrm{H}_{2} \mathrm{O}-\mathrm{CN}$, indicating a lower rate of recombination and a longer lifetime of charge carriers, which improves the photocatalytic activity. The order of PL intensity was (Figures 5d and S4d): FCN $<1: 4 C N<1: 3 C N<1: 1 C N$; therefore, FCN exhibits the lowest rate of recombination of photoexcited electrons and holes.

The mechanism of transfer of the photogenerated charge carriers was studied by electrochemical testing. The photocurrent responses of CN and FCN are shown in Figure 5e. The composite efficiency of photogenerated electrons can be obtained by analyzing the transient photocurrent response [23]. Evidently, further heating enhances the photocurrent generation. FCN delivered a six times higher photocurrent response than that of $C N$. This result reveals that the separation efficiency of photoelectrons and holes for FCN is higher than that for the CN sample, which explains the higher photocatalytic activity of FCN.

Figures $5 \mathrm{f}$ and $\mathrm{S} 6$ show the UV-vis DRS of the obtained samples. Except two samples $\left(0 \mathrm{H}_{2} \mathrm{O}-\mathrm{CN}\right.$ and $\left.50 \mathrm{H}_{2} \mathrm{O}-\mathrm{CN}\right)$ with nearly zero absorbance, the spectrum of $10 \mathrm{H}_{2} \mathrm{O}-\mathrm{CN}$ was redshifted compared to that of $20 \mathrm{H}_{2} \mathrm{O}-\mathrm{CN}$, and the absorbance peaks of $10 \mathrm{H}_{2} \mathrm{O}-\mathrm{CN}$ and $20 \mathrm{H}_{2} \mathrm{O}-\mathrm{CN}$ all lay between 400 and $800 \mathrm{~nm}$. These results indicate that appropriately controlling the water content in precursor increases the optical absorptivity in the visible region. The optical bandgap values of these two samples are obtained from Figure S6b, which shows similar bandgap values of 2.39 and $2.42 \mathrm{eV}$ for $10 \mathrm{H}_{2} \mathrm{O}-\mathrm{CN}$ and $20 \mathrm{H}_{2} \mathrm{O}-\mathrm{CN}$, respectively. Figure S6c shows the UV-vis absorption intensities at different ratios of melamine to 2,5-thiophenedicarboxylic acid. The absorbance regions of $1: 4 \mathrm{CN}$ and 1:3CN were redshifted compared to those of $1: 1 \mathrm{CN}, 1: 2 \mathrm{CN}$ and $1: 5 \mathrm{CN}$, and remained at a $20 \%$ absorbance ratio even at $800 \mathrm{~nm}$. The FCN sample prepared with further heating exhibited increases in the bandgap values compared to the other samples. The decrease in absorption and the larger bandgap may be due to the lighter color of the FCN sample reducing the light absorption following further heating. 

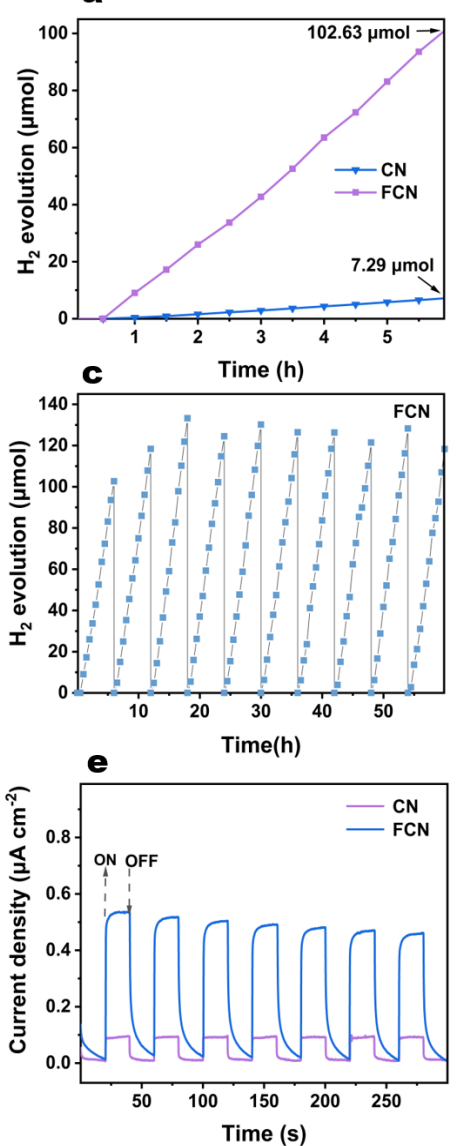

b
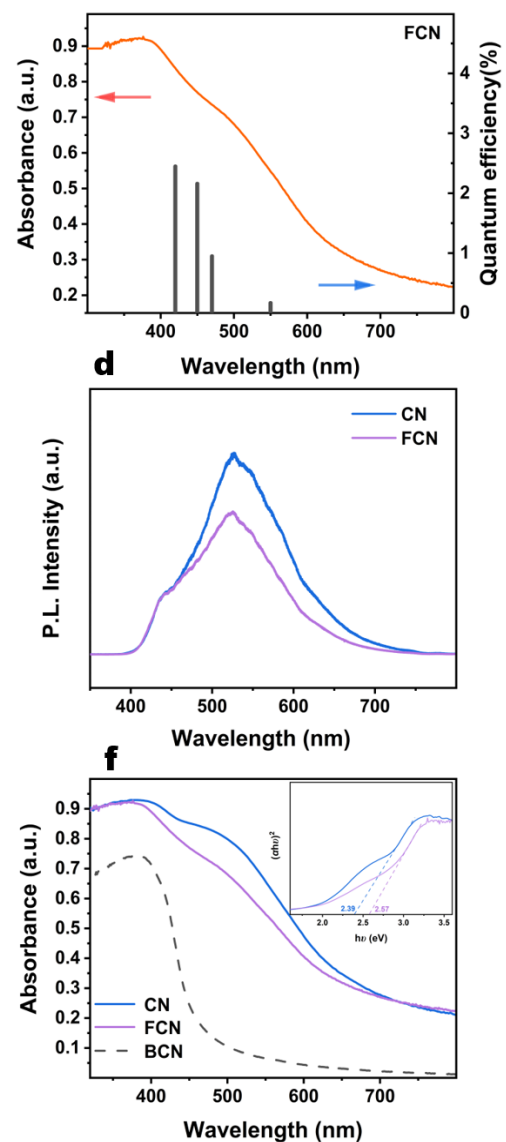

Figure 5. (a) Photocatalytic $\mathrm{H}_{2}$ evolution of $\mathrm{CN}$ and FCN. (b) The AQY against the light absorption wavelength of FCN. (c) The $\mathrm{H}_{2}$ evolution cycling plots for FCN through $60 \mathrm{~h}$ of operation. (d) PL spectra for CN and FCN. (e) Transient photocurrent responses of CN and FCN. (f) UV-vis diffuse reflectance spectra and plots of $(\alpha h v)^{2}$ vs. photon energy $(h v)$ of $\mathrm{CN}$ and FCN.

During photocatalysis using $\mathrm{CN}$ and FCN under visible-light irradiation, active oxygen species such as the superoxide radical $\left(\cdot \mathrm{O}^{2-}\right)$ and the hydroxyl radical $(\cdot \mathrm{OH})$ were detected as key initiators in methanol and water, respectively [1]. We have studied the relationships between the properties of the samples and the generation of $\cdot \mathrm{O}^{2-}$ and $\cdot \mathrm{OH}$ under visible-light irradiation through ESR spectroscopy. CN and FCN samples were studied in the dark where they emitted very weak signals, indicating that the $\cdot \mathrm{O}^{2-}$ radical is very sensitive to the light emitted by these two samples (Figure 6a,b). Additionally, a sharp and narrow $\cdot \mathrm{O}^{2-}$ signal was recorded in situ when the samples were exposed to visible light, which confirms the visible-light-induced formation of the radical ligand [28]. $\mathrm{O}^{2-}$ radicals can be transferred out to the interface to reduce the $\mathrm{O}^{2}$ into $\cdot \mathrm{O}^{2-}$. By comparison, it is clearly seen that $\mathrm{CN}$ and FCN samples can greatly enhance the generation of $\cdot \mathrm{OH}$ radicals when irradiated by visible light compared to when left in darkness. The rate of generation of the $\cdot \mathrm{OH}$ radical increases with the intensity of the incident radiation [29]. The . $\mathrm{OH}$ radicals can be transferred out to the interface to convert water or $\mathrm{OH}$ - into $\cdot \mathrm{OH}$. The rate of conversion is much higher under illumination than that without, suggesting that these three samples can use light to produce $\cdot \mathrm{O}^{2-}$ and $\cdot \mathrm{OH}$ efficiently. 

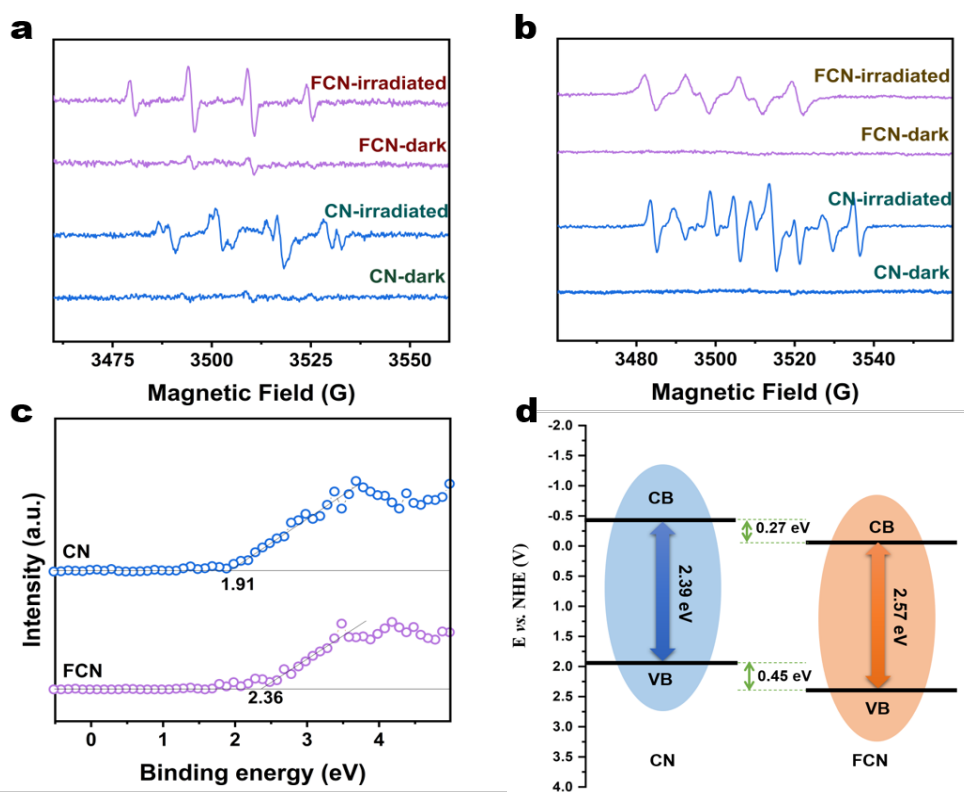

Figure 6. (a) ESR spectra of $\mathrm{CN}$ and FCN in darkness and under visible-light irradiation to evaluate the generation of $\mathrm{O}^{2-}$ radicals (b) ESR spectra of $\mathrm{CN}$ and FCN in the dark and under visiblelight irradiation to evaluate the generation of $\cdot \mathrm{OH}$ - radicals. (c) VB-XPS spectra of $\mathrm{CN}$ and FCN. (d) Schematic of the band structures of $\mathrm{CN}$ and FCN.

The energy gaps between the valence band maximum (VBM) and the conduction band minimum (CBM) were calculated from the VB-XPS spectra (Figure 6c) to be 2.36 and $1.91 \mathrm{eV}$ for $\mathrm{FCN}$ and $\mathrm{CN}$, respectively, which are lower than the band gap of $2.7 \mathrm{eV}$ for BCN. The carbon vacancy reduces the CBM, thereby narrowing the band gap. By analyzing the UV-vis spectra, the CBM of FCN and CN were calculated to be $-0.21 \mathrm{eV}$ and $-0.48 \mathrm{eV}$, respectively. The band structures of $\mathrm{FCN}$ and $\mathrm{CN}$ were proposed as illustrated in the schematic diagram in Figure 6d. The VBM and the CBM shifted to more positive potentials following further heating, which influenced the electronic structures of the conduction or valence bands. The redox potential for $\mathrm{H}^{+} / \mathrm{H}_{2}$ increases with increasingly positive values of the CBM for FCN, which shortens the transition path of the photogenerated electrons [30]. In addition, the higher specific surface area provides a larger number of active sites for $\mathrm{H}^{+}$ reduction during photocatalytic reactions, which expedites the photocatalytic production of $\mathrm{H}_{2}$ for $\mathrm{FCN}$.

\section{Conclusions}

In this study, we pioneered the fabrication of ultrathin fibrous CTF-derived $\mathrm{C}_{3} \mathrm{~N}_{4}$ via thermopolymerization followed by further thermal treatment. The prepared FCN retained the internal pore structure of the covalent organic framework. Calcination in argon atmosphere proved to be an effective method of creating carbon vacancies, which can inhibit carrier recombination by capturing photogenerated electrons and holes. FCN possessed higher specific surface area and delivered 66 times higher generation of $\mathrm{H}_{2}$ under visible-light illumination during photocatalysis compared to $\mathrm{BCN}$. This sample presented a wider light absorption region and its AQYs were calculated to be $2.45 \%$ and $2.16 \%$ at 420 and $450 \mathrm{~nm}$, respectively. This study publishes a novel synthetic strategy for a highly efficient photocatalyst derived from a covalent organic framework for use in hydrogen production.

Supplementary Materials: The following are available online at https:/ / www.mdpi.com/article / 10.3390/app11167222/s1, Figure S1: (a,b) FTIR spectra for $\mathrm{xH}_{2} \mathrm{O}-\mathrm{CN}, 1: x \mathrm{CN}$ and FCN. (c,d) FTIR spectra for $\mathrm{xH}_{2} \mathrm{O}-\mathrm{CTF}$ and 1:xCTF. (e,f) XRD patterns for $\mathrm{xH}_{2} \mathrm{O}-\mathrm{CN}, 1: \mathrm{x} \mathrm{CN}$ and FCN, Figure S2: (a-d) SEM images for $\mathrm{xH}_{2} \mathrm{O}-\mathrm{CN}$, Figure S3: (a-e) SEM images for 1:xCN, Figure S4: $(\mathrm{a}, \mathrm{b})$ Photocatalytic $\mathrm{H}_{2}$ evolution of $\mathrm{xH}_{2} \mathrm{O}, 1: x C N$ and FCN. (c,d) PL spectra for $\mathrm{xH}_{2} \mathrm{O}, 1: \mathrm{xCN}$ and FCN, Figure S5: The $\mathrm{H}_{2}$ 
evolution cycling plots for $\mathrm{CN}$ through $24 \mathrm{~h}$ of operation, Figure S6: (a) UV-vis diffuse reflectance spectra of $\mathrm{xH}_{2} \mathrm{O}$. (b) Plots of $(\alpha h v)^{2}$ vs. photon energy $(h v)$ of $\mathrm{xH}_{2} \mathrm{O}$. (c) UV-vis diffuse reflectance spectra of 1:xCN and FCN. (d) Plots of $(\alpha h v)^{2}$ vs. photon energy $(h v)$ of 1:xCN and FCN, Table S1: $\left(\mathrm{C}_{3}+\mathrm{C}_{2}\right)$ type of hexagonal COFs.

Author Contributions: L.Z. analyzed the data and wrote the paper, A.W. and M.Z. synthesized and characterized the samples. Z.J. and H.Y. contributed reagents/materials/analysis tools. M.W. designed the experiments and review the paper. All authors have read and agreed to the published version of the manuscript.

Funding: This work was supported by the Post-Doc Research Project of SZTU (W201960002440008), Guangdong Provincial Department of Education Young Innovative Talents Project (2019KQNCX179).

Institutional Review Board Statement: Not Applicable.

Informed Consent Statement: Not Applicable.

Data Availability Statement: Not Applicable.

Conflicts of Interest: The authors declare no conflict of interest.

\section{References}

1. Hoffmann, M.R.; Choi, W.; Bahnemann, D.W. Environmental Applications of Semiconductor Photocatalysis. Chem. Rev. 1995, 95, 69-96. [CrossRef]

2. Tachibana, Y.; Vayssieres, L.; Durrant, J.R. Artificial photosynthesis for solar water-splitting. Nat. Photonics 2012, 6, 511-518. [CrossRef]

3. Schlapbach, L.; Züttel, A. Hydrogen-storage materials for mobile applications. Nature 2001, 414, 353-358. [CrossRef] [PubMed]

4. Jin, M.; Sumitani, T.; Sato, H.; Seki, T.; Ito, H. Mechanical-Stimulation-Triggered and Solvent-Vapor-Induced Reverse SingleCrystal-to-Single-Crystal Phase Transitions with Alterations of the Luminescence Color. J. Am. Chem. Soc. 2018, 140, 2875-2879. [CrossRef] [PubMed]

5. Cao, S.; Yu, J. g- $\mathrm{C}_{3} \mathrm{~N}_{4}$-Based Photocatalysts for Hydrogen Generation. J. Phys. Chem. Lett. 2014, 5, 2101-2107. [CrossRef]

6. Zhang, J.; Zhang, G.; Chen, X.; Lin, S.; Möhlmann, L.; Do, D.G.; Lipner, G.; Antonietti, M.; Blechert, S.; Wang, X. Co-Monomer Control of Carbon Nitride Semiconductors to Optimize Hydrogen Evolution with Visible Light. Angew. Chem. Int. Ed. 2012, 165, 3183-3187. [CrossRef] [PubMed]

7. Zhao, W.; Yang, G.; Wang, S.; He, H.; Sun, C.; Yang, S. A novel ternary plasmonic photocatalyst: Ultrathin g-C $\mathrm{N}_{4} \mathrm{~N}_{4}$ nanosheet hybrided by $\mathrm{Ag} / \mathrm{AgVO}_{3}$ nanoribbons with enhanced visible-light photocatalytic performance. Appl. Catal. B Environ. 2015, 165, 335-343. [CrossRef]

8. Yu, X.; Ng, S.F.; Putri, L.K.; Tan, L.L.; Mohamed, A.R.; Ong, W.J. Point-Defect Engineering: Leveraging Imperfections in Graphitic Carbon Nitride $\left(\mathrm{g}-\mathrm{C}_{3} \mathrm{~N}_{4}\right.$ ) Photocatalysts toward Artificial Photosynthesis. Small 2012, 2006851. [CrossRef]

9. Zhu, Z.; Pan, H.; Murugananthan, M.; Gong, J.; Zhang, Y. Visible light-driven photocatalytically active g- $\mathrm{C}_{3} \mathrm{~N}_{4}$ material for enhanced generation of $\mathrm{H}_{2} \mathrm{O}_{2}$. Appl. Catal. B Environ. 2018, 232, 19-25. [CrossRef]

10. Li, S.; Dong, G.; Hailili, R.; Yang, L.; Li, Y.; Wang, F.; Zeng, Y.; Wang, C. Effective photocatalytic $\mathrm{H}_{2} \mathrm{O}_{2}$ production under visible light irradiation at g- $\mathrm{C}_{3} \mathrm{~N}_{4}$ modulated by carbon vacancies. Appl. Catal. B Environ. 2016, 190, 26-35. [CrossRef]

11. Liang, Q.; Li, Z.; Huang, Z.-H.; Kang, F.; Yang, Q.-H. Holey Graphitic Carbon Nitride Nanosheets with Carbon Vacancies for Highly Improved Photocatalytic Hydrogen Production. Adv. Funct. Mater. 2015, 25, 6885-6892. [CrossRef]

12. Huang, S.; Ge, F.; Yan, J.; Li, H.; Zhu, X.; Xu, Y.; Xu, H.; Li, H. Synthesis of carbon nitride in moist environments: A defect engineering strategy toward superior photocatalytic hydrogen evolution reaction. J. Energy Chem. 2021, 54, 403-413. [CrossRef]

13. Jin, Z.; Jiang, X.; Zhang, Q.; Huang, S.; Zhang, L.; Huang, L.; He, T.; Zhang, H.; Ohno, T.; Ruan, S.; et al. Infrared response in photocatalytic polymeric carbon nitride for water splitting via an upconversion mechanism. Commun. Mater. 2020, 1, 90. [CrossRef]

14. Xu, Y.; He, X.; Zhong, H.; Singh, D.J.; Zhang, L.; Wang, R. Solid salt confinement effect: An effective strategy to fabricate high crystalline polymer carbon nitride for enhanced photocatalytic hydrogen evolution. Appl. Catal. B Environ. 2019, 246, 349-355. [CrossRef]

15. Wang, Y.; Du, P.; Pan, H.; Fu, L.; Zhang, Y.; Chen, J.; Du, Y.; Tang, N.; Liu, G. Increasing Solar Absorption of Atomically Thin 2D Carbon Nitride Sheets for Enhanced Visible-Light Photocatalysis. Adv. Mater. 2019, 31, 1807540. [CrossRef]

16. Calik, M.; Auras, F.; Salonen, L.M.; Bader, K.; Grill, I.; Handloser, M.; Medina, D.D.; Dogru, M.; Löbermann, F.; Trauner, D. Extraction of photogenerated electrons and holes from a covalent organic framework integrated heterojunction. J. Am. Chem. Soc. 2014, 1, 17802-17807. [CrossRef]

17. Huang, N.; Wang, P.; Jiang, D. Covalent organic frameworks: A materials platform for structural and functional designs. Nat. Rev. Mater. 2016, 1, 16068. [CrossRef]

18. Peng, J.; Chen, X.; Ong, W.-J.; Zhao, X.; Li, N. Surface and Heterointerface Engineering of 2D MXenes and Their Nanocomposites: Insights into Electro- and Photocatalysis. Chem 2019, 5, 18-50. [CrossRef] 
19. Cao, S.; Low, J.; Yu, J.; Jaroniec, M. Polymeric photocatalysts based on graphitic carbon nitride. Adv. Mater. 2015, 27, $2150-2176$. [CrossRef]

20. Ohno, T.; Murakami, N.; Koyanagi, T.; Yang, Y. Photocatalytic reduction of $\mathrm{CO}_{2}$ over a hybrid photocatalyst composed of WO 3 and graphitic carbon nitride $\left(\mathrm{g}-\mathrm{C}_{3} \mathrm{~N}_{4}\right)$ under visible light. J. $\mathrm{CO}_{2}$ Util. 2014, 6, 17-25. [CrossRef]

21. Kong, L.; Ji, Y.; Dang, Z.; Yan, J.; Li, P.; Li, Y.; Liu, S.F. g-C $\mathrm{C}_{3} \mathrm{~N}_{4}$ Loading Black Phosphorus Quantum Dot for Efficient and Stable Photocatalytic $\mathrm{H}_{2}$ Generation under Visible Light. Adv. Funct. Mater. 2018, 28, 1800668. [CrossRef]

22. Zhang, L.; Jin, Z.; Huang, S.; Huang, X.; Xu, B.; Hu, L.; Cui, H.; Ruan, S.; Zeng, Y.-J. Bio-inspired carbon doped graphitic carbon nitride with booming photocatalytic hydrogen evolution. Appl. Catal. B Environ. 2019, 246, 61-71. [CrossRef]

23. Sun, C.; Zhang, H.; Liu, H.; Zheng, X.; Zou, W.; Dong, L.; Qi, L. Enhanced activity of visible-light photocatalytic H2 evolution of sulfur-doped $g-\mathrm{C}_{3} \mathrm{~N}_{4}$ photocatalyst via nanoparticle metal $\mathrm{Ni}$ as cocatalyst. Appl. Catal. B Environ. 2018, 235, 66-74. [CrossRef]

24. Liu, S.; Li, D.; Sun, H.; Ang, H.M.; Tade, M.O.; Wang, S. Oxygen functional groups in graphitic carbon nitride for enhanced photocatalysis. J. Colloid Interface Sci. 2016, 468, 176-182. [CrossRef] [PubMed]

25. Li, J.; Shen, B.; Hong, Z.; Lin, B.; Gao, B.; Chen, Y. A facile approach to synthesize novel oxygen-doped g- $\mathrm{C}_{3} \mathrm{~N}_{4}$ with superior visible-light photoreactivity. Chem. Commun. 2012, 48, 12017-12019. [CrossRef]

26. Yu, Y.; Yan, W.; Wang, X.; Li, P.; Gao, W.; Zou, H.; Wu, S.; Ding, K. Surface Engineering for Extremely Enhanced Charge Separation and Photocatalytic Hydrogen Evolution on $\mathrm{g}_{3} \mathrm{C}_{3} \mathrm{~N}_{4}$. Adv. Mater. 2018, 30, 1705060. [CrossRef] [PubMed]

27. Tahir, M.; Cao, C.; Mahmood, N.; Butt, F.K.; Mahmood, A.; Idrees, F.; Hussain, S.; Tanveer, M.; Ali, Z.; Aslam, I. Multifunctional g- $\mathrm{C}_{3} \mathrm{~N}_{4}$ nanofibers: A template-free fabrication and enhanced optical, electrochemical, and photocatalyst properties. ACS Appl. Mater. Interfaces 2014, 6, 1258-1265. [CrossRef]

28. Quah, H.S.; Chen, W.; Schreyer, M.K.; Yang, H.; Wong, M.W.; Ji, W.; Vittal, J.J. Multiphoton harvesting metal-organic frameworks. Nat. Commun. 2015, 6, 7954. [CrossRef]

29. Li, X.; Pi, Y.; Wu, L.; Xia, Q.; Wu, J.; Li, Z.; Xiao, J. Facilitation of the visible light-induced Fenton-like excitation of $\mathrm{H}_{2} \mathrm{O}_{2}$ via heterojunction of g- $\mathrm{C}_{3} \mathrm{~N}_{4} / \mathrm{NH}_{2}$-Iron terephthalate metal-organic framework for MB degradation. Appl. Catal. B Environ. 2017, 202, 653-663. [CrossRef]

30. Wang, F.; Wang, Y.; Feng, Y.; Zeng, Y.; Xie, Z.; Zhang, Q.; Su, Y.; Chen, P.; Liu, Y.; Yao, K.; et al. Novel ternary photocatalyst of single atom-dispersed silver and carbon quantum dots co-loaded with ultrathin $\mathrm{g}-\mathrm{C}_{3} \mathrm{~N}_{4}$ for broad spectrum photocatalytic degradation of naproxen. Appl. Catal. B Environ. 2018, 221, 510-520. [CrossRef] 